\title{
PITFALLS IN THE ESTIMATION OF SEISMIC HAZARD
}

\author{
Warwick D. Smith*
}

SUMMARY:

Computer catalogues of earthquakes make it rather simple to extract lists of earthquakes that are likely to have affected sites of interest during the historical past, and it is tempting to use such lists for estimation of seismic hazard. What must be borne in mind, however, is that the seismological record is only part of the information required for hazard estimates, that the earthquake catalogue may not be complete and that early epicentres and magnitudes may have large uncertainties. If ground motion is estimated from these approximate epicentres, further uncertainties creep in. Some myths about the concept of return period are exploded, and a bibliography of studies relevant to seismic hazard in New Zealand is presented.

\section{INTRODUCTION :}

With the availability of computer catalogues of earthquakes, from which lists of events satisfying a variety of criteria can be extracted easily, it has become a popular exercise to use these catalogues to estimate seismic hazard. Insurance companies, for instance, often prefer to make their own estimates of hazard, and sometimes base them on earthquake magnitudes and locations alone. It is true that seismologists in New Zealand have consistently maintained that it is not appropriate to regard earthquake activity here as being confined to known faults, because seismicity is observed to be spatially diffuse. A geometrical approach to seismic hazard in terms of line sources (eg. Cornell, 1968) is therefore not appropriate in New Zealand, and it is necessary to use actual earthquake locations. But there are traps for the unwary in this type of calculation. It should not be attempted without a careful appraisal of the limitations inherent in the procedure.

The Seismological Observatory, Wellington, can make available lists of earthquakes which occurred in given areas, satisfying given criteria (see Smith, 1976a). When the availability of this file was announced, it was suggested that users discuss their search criteria and the limitations of the data with the observatory. But it has become apparent that not all who have made use of the data are aware of the problems in estimating seismic hazard. This paper is an attempt to discuss some of those problems.

The term "Seismic Hazard" is used here in the sense in which Ciborowski (1981) distinguished it from "Seismic Risk" with the equation

Risk = Vulnerability $\mathrm{x}$ Hazard

"Hazard" is the probability of occurrence of damaging ground motion, whereas "Risk" includes the nature and use of buildings. Sometimes economic considerations are included by including a third factor ( $\mathrm{X}$ Value) on the right hand side of the equation. Vere-Jones (1973)

*Seismological Observatory, DSIR, Wellington. similarly distinguished between Risk and Hazard, although he used different terminology. In this paper I shall be concerned only with Hazard.

\section{ADEQUACY OF SEISMOLOGICAL DATA}

Reports of earthquakes from countries with a very long history, such as China, Japan and Turkey, show that there can be active and quiescent periods, often some centuries in duration. To base estimates of seismic hazard on the events of the last century and a half (in New Zealand's case) is therefore to tell only part of the story. Some geological inference must also be made about activity over a much longer period, in order to establish the true mean rate of occurrence, and consideration must be given to the tectonic setting. While it is recognized that the events of the last century might be a reasonable indicator of the activity in the next, geological information is still important (Adams, 1975). The widely used results for New Zealand (Smith, 1976b) which were based only on historical seismicity were not published without a carefully worded warning that they did not take account of geological data. Some users seem to have disregarded this warning.

A new study is currently in progress which seeks to combine historical seismological data, inferences from geological field studies and tectonic considerations (Smith and Berryman, in preparation). study will revise the 1976 estimates. Successful integration of seismological and geological information has recently been achieved in the USSR (Medvedev, 1976) and in several western countries.

\section{COMPLETENESS OF SEISMOLOGICAL DATA:}

The New Zealand seismological network, as currently configured, is capable of detecting and locating all earthquakes of magnitude 4.0 within New Zealand and some distance to the north and south. In parts of the country the threshold is somewhat lower. But before the mid-1960's the catalogue of earthquakes is not complete below about magnitude 4.5 and before 1940 is much less complete. In fact, the computer catalogue for the years before 1940 is not the result of any careful revision but contains only a 
list of large shocks listed by various workers. It is hoped that it will eventually be possible to revise all early seismological recordings to document the seismicity as well as possible, but even this will provide an incomplete list because there were only a handful of seismographs in the country, and they were of a quality much inferior to modern instruments. Prior to 1900 the record is dependent solely on felt information, and the sparse nature of the settlement of the country means that the record must by its very nature be a very incomplete one.

Calculations of risk which are based on the earthquake catalogue must therefore take into account the varying degrees of completeness claimed for it.

\section{ACCURACY OF SEISMOLOGICAL DATA:}

Since the mid-1960's it has usually been possible to locate earthquakes within New Zealand with an accuracy of better than $20 \mathrm{~km}$. This is not the result of a formal study of standard errors, but rather an estimate which may be subjective. An error as small as this is a consequence of the deployment of nearly thirty shortperiod seismographs throughout the country. Random errors were greater when there were fewer stations, but there are systematic errors as well, related to the complexity of the velocity structure. The $20 \mathrm{~km}$ figure is judged to be an approximate measure of absolute error, but it will vary throughout the country, for deep earthquakes, and with other factors.

Accuracy of the epicentral coordinates is indicated in two ways in the Seismological Observatory lists. First, the epicentre is given to the nearest degree, tenth of a degree or hundredth of the degree, as appropriate. The epicentres of those early shocks that are given to the nearest degree must be regarded as extremely unreliable. The locations are usually based on a handful of felt reports, and no accuracy is claimed for these events.

From 1955 to 1963 a quality factor was assigned to each earthquake, as a letter A, B, C or D. Shocks classified $A$ were regarded as being accurate to within 5 miles $(8 \mathrm{~km})$, B to within 10 miles $(16 \mathrm{~km})$, $C$ to within 15 miles $(25 \mathrm{~km})$, and $D$ were more uncertain. This classification appears in the column headed SE (for Standard Error) in the Observatory lists, but it was a rather subjective classification and should not be regarded as reliable. Since 1964 the computer location of earthquakes has provided a measure of the standard error of all the phase arrivals used in the computation, which is a measure of the uncertainty in the location. This is listed, in seconds, in the SE column. Latitude and longitude are given to two decimals of a degree, but there is an uncertainty in the epicentre which depends not only on the standard error but also on the number of readings used to determine the solution. This is listed in the next column NP (number of phases). There is no simple relationship between these various quantities, but the following formula could be used: epicentral error $=\frac{30 \times \mathrm{SE}}{\sqrt{\mathrm{NP}-3}}$

This relation is approximate and empirical. It is not the result of any particular study, experimental or theoretical, but simply expresses the judgement that the error is likely to be related to the standard error of the residuals and the number of phases used, in an expression of this form. The scale factor 30 was chosen to give realistic error figures, expressed in kilometres.

\section{ACCURACY OF ESTIMATED GROUND MOTION}

An important consequence of errors in epicentres involves the calculation of the intensities likely to have been felt at given locations. A formula for likely intensity, given the location of interest and the coordinates of the earthquake, together with its magnitude, was developed by Smith (1976b). So it is possible to compute the intensities likely to have been felt at any given locality, due to all historical earthquakes, and indeed to select those occasions when the likely intensity exceeded a specified threshold. This likely intensity, if requested, appears on the Observatory printouts, given to one place of decimals. This decimal should be truncated, not rounded, to give the likely MM intensity.

This calculation is highly susceptible to errors in the location of the earthquake, particularly at short distances. For instance, an earthquake on 1929 May 7 is listed in the catalogue as having occurred at $40^{\circ} \mathrm{S}, 175 \mathrm{O}^{\mathrm{E}}$ (no decimals). The magnitude is given as Class $B$, a classification for early shocks which indicates the range 6.0 to 7.5 . When attempting to calculate the likely intensity at Wanganui, say, it is necessary to assume a location of $40.00^{\circ} \mathrm{S}, 175.00^{\circ} \mathrm{E}$, which happens to be very close to Wanganui, and a magnitude in mid-range, say 6.8 . The result is a calculated intensity of MMIX, whereas the actual reported intensity on that occasion was MMV to MMVI. The disparity between actual and calculated figures illustrates the importance of the quoted accuracy of the epicentral coordinates and the magnitude.

\section{THE CONCEPT OF RETURN PERIOD:}

"Return Period" is a term commonly used for the reciprocal of the annual frequency of occurrence. Statistical studies of earthquake occurrence commonly assume a Poisson law, under which the likelihood of occurrence at any particular time is independent of all preceding events. That is, a Poisson process can be said to have no memory. This is clearly not ideal for earthquakes, which are dependent on the buildup of stress within the earth, but such is the sporadic nature of their occurrence that the simple Poisson model serves as a first approximation. Some statisticians (eg. Vere-Jones, 1975) have experimented with other stochastic models, in particular attempting to model the commonly observed 
clustering of large earthquakes.

The Poisson model can be used to quantify the occurrence of large earthquakes within a given region, or the occurrence of strong ground motion at a particular place. Needless to say, these are not the same, and confusion between the two can lead to such meaningless questions as "What is the mean return period for large earthquakes in Wellington?" In hazard studies it is usual to endeavour to estimate the rate of occurrence of strong ground motion at given sites, and that is the sense in which the Poisson model is used here.

If there are $\mathrm{N}$ occurrences in $\mathrm{T}$ years the mean annual rate of occurrence is $\mathrm{N} / \mathrm{T}$. The annual probability of occurrence is

$\mathrm{p}=1-\exp (-\mathrm{N} / \mathrm{T})$

which is close to $\mathrm{N} / \mathrm{T}$ if this quantity is small. The so-called Return Period is just $\mathrm{T} / \mathrm{N}$, or approximately $1 / \mathrm{p}$, but it is a mistake to assume that a recurrence of the event is most likely after an interval approximately equal to this. In fact, according to the Poisson model, the first year is the most likely. Figure la shows the probability that the next event will occur in any particular year, from the first to the hundredth, given an annual probability of 0.02 , or a return period of 50 years. The mean of the distribution is 50 years. The actual probability function for year $n$ is

$P=(1-p)^{n-1} p$

which is approximately equal to $\mathrm{p}$ exp $(-(n-1) p)$ for $p$ small.

Another way of expressing the probabilities is shown in Figure $1 \mathrm{~b}$. This is the probability that the event will occur within a given period of time. It is thus the cumulative probability distribution. This distribution was referred to by Dibble (1956) in estimating risks in the Wellington area. It is important to recognise, however, that this represents the risk as estimated at year zero. It is not valid to say "the return period is 50 years, it is 80 years since the last large event, so the probability of another occurring this year is high." Not valid, that is, on the basis of the Poisson model. One might well arrive at such a conclusion on other grounds, such as the buildup of stress in the earth, seismic cycles, etc. But according to the Poisson model, the probability in any particular year is given by equation (2). This illustrates some of the shortcomings of the Poisson model in this application.

\section{PUBLISHED ESTIMATES OF EARTHQUAKE HAZARD IN NEW ZEALAND:}

Various workers have attempted to quantify earthquake hazard in New Zealand, either for the whole country or for a part of it. These studies are listed below, with a brief comment about each. The list includes not anly those that assign frequencies of occurrence to strong ground motion in various localities, but also those that estimate the frequency of occurrence of damaging earthquakes or of fault movement, these being related parameters. They are presented in chronological order, and no attempt has been made to compare the validity of the individual studies.

Bastings and Hayes (1935) analysed earthquake felt information for the period 1848 to 1934. This included over 6,000 felt earthquakes. They divided the country into 19 areas and summarized the number of earthquakes felt in each area, and the maximum intensities reported.

Hayes (1936a) showed that there is a systematic variation in intensity maps throughout the country, in particular that the distribution of intensity with distance from the epicentre in the Hawke's Bay earthquake of 1931 was very different from that in the Buller earthquake of 1929.

Hayes (1936b) tabulated the frequency of occurrence of various Rossi-Forel intensity levels at a selection of New Zealand cities and towns. Data: 1834 to 1935 .

Hayes (1941) divided New Zealand into four regions, based on the frequency of occurrence of felt earthquakes and on maximum intensities reported. Data: 1835 to 1940. This paper was later substantiated (Hayes, 1943) by a study of instrumentally located earthquakes.

Dibble (1956) estimated earthquake hazard in the Wellington area. He considered the volume of rock strained in a large earthquake and concluded that a destructive event every 40 years is a very conservative estimate. Data: 1835 to 1955.

Dick (1965) performed an extremevalue analysis of earthquake magnitudes within the main seismic region, and calculated the frequencies of occurrence of large earthquakes throughout the region. Data: 1945-61.

Clark et al (1965) identified Quaternary tectonic deformation throughout New Zealand. They considered the size of the area of destruction in a large earthquake and divided the country into four zones of different severity.

Dickenson and Adams (1967) performed a statistical analysis of the seismicity and presented contour maps showing the frequency of occurrence of earthquakes both shallow and deep. Data: 1942-61.

Lensen (1968) analysed progressive fault displacement at the Branch River, South Island. He assessed the average recurrence interval of the transcurrent Wairau Fault to be c. 900 years over the past 18,000 years.

Eiby (1971) divided New Zealand into two regions and obtained overall rates of activity and b-values for each. He used instrumental data 1955-70 for small thresholds and historical data for large events. 
Lensen (1976) reiterated the 900 year recurrence interval for faulting on the Wairau fault and compared it with the rate of present-day elastic strain accumulation derived from repeated triangulation observations.

The Standards Association of $\mathrm{NZ}$ (1976) published its code of practice which includes earthquake provisions. There are three zones and provision within each for different subsoil conditions. This publication is a revision of earlier ones, and is included here as a representative of various code statements which exist.

Smith (1976b) used isoseismal maps to develop an empirical formula for Modified Mercalli intensity as a function of magnitude and epicentral distance, and used it with the historical record of large earthquakes to estimate the frequency of occurrence of damaging intensities, presented in the form of contour maps. Data: 1840 to 1975. The full detail of the analysis was presented in two subsequent papers (Smith 1978a, b).

Walley (1976) performed a rigorous statistical analysis of reported felt intensities to develop an intensity formula for Modified Mercalli intensity, given magnitude and epicentral distance, and used it to estimate the frequency of occurrence of high intensities. Data: 1942-69.

Lensen (1977) prepared a location map of active faults, indicating tectonic regimes.

Adams (1980) postulated a recurrence interval of c. 500 years for fault movement associated with earthquakes of magnitude 8 in the central part of the Alpine Fault.

Berryman (1980) endeavoured to estimate recurrence intervals in the Buller-NW Nelson region, as Lensen (1968, 1976) had done for the Wairau Fault.

Matuschka (1980) developed empirical formulae for peak acceleration and Modified Mercalli intensity as functions of magnitude and distance, and used them with the earthquake catalogue to produce contour maps of the frequency of occurrence of damaging levels of peak ground motion. He also prepared site-dependent ground motion spectra for a hypothetical site in Wellington. Data: 1850-1975.

Peek (1980) set up a seismicity model for New Zealand, from considerations of both seismological and geological history. He then chose a suitable attenuation model and computed risk spectra for several specific sites and presented a contour map of New Zealand showing spectral accelerations corresponding to a natural period of $0.2 \mathrm{~s}$ and a return period of 150 years. The seismicity model was subsequently published by Peek at al (1981).

Berrill et al (1981) proposed a seismic zoning for New Zealand, with continuous variation of the spectral parameters between zones. They presented a contour map of average annual energy release in earthquakes to support the empirical zoning.

\section{CONCLUSIONS}

While it may be tempting to use lists of known earthquakes to estimate seismic hazard, there are pitfalls which may not be apparent. List of earthquakes are usually incomplete and individual epicentres and magnitudes may have large uncertainties, particularly in the early historical period. If the likely ground motion is calculated from these uncertain epicentres, yet another error factor is introduced and the results can be highly misleading. A proper estimate of earthquake hazard entails an analysis of both seismological and geological data.

There are popular misconceptions about the term "Return Period". In particular, the Poisson likelihood of recurrence at or near the Return Period is in fact no greater than at any other time. The poisson model, on the assumption of which the concept of Return Period is based, is probably not the most appropriate statistical model, but it serves a useful purpose if one is aware of its shortcomings.

The bibliography of studies relevant to earthquake hazard should serve as a useful guide to work on this subject in New Zealand.

\section{ACKNOWLEDGEMENTS :}

I am grateful to Mr K.R. Berryman for his making me aware of some of the geological work, and to Mr G.A. Eiby and Dr E.G.C. Smith for their comments on the manuscript.

\section{REFERENCES :}

Adams, J. 1980. "Paleoseismicity of the Alpine Fault Seismic Gap, New Zealand" Geology, $8,72-6$.

Adams, R.D., 1975. "Developments in Studies of Earthquake Risk". Bull. N.Z. Nat. Soc. Earthq. Eng. 8, $1-11$.

Bastings, L. and Hayes, R.C. 1935. "Earthquake Distribution in New Zealand 1848-1934". N.Z. J. Sci. Tech. XVI, $308-12$.

Berrill, J.B.; Priestley, M.J.N. and Peek R. 1981. "Further Comments on Seismic Design Loads for Bridges". Bull. N.Z. Nat. Soc. Earthq. Eng. 14, 3-11.

Berryman, K.R. 1980. "Late Quaternary Movement on the White Creek Fault, South Island, New Zealand! N.Z. J. Geol. Geophys. 23, 93-101.

Ciborowski, A. 1981. "Urban Design and Physical Planning as Tools to Make Cities Safer in EarthquakeProne Areas". Roy. Soc. N.Z. Bull 5 (Misc. Series), 55-65.

Clark, R.H., Dibble, R.R., Fyfe, H.E. Lensen, G.J. and Suggate, R.P. 1965. "Tectonic and Earthquake Risk Zoning." 
Trans. Roy. Soc. N.Z. (General) 1, $113-126$.

Dibble, R.R. 1956. "Earthquake Risks in the Wellington Area." N.Z. Science Review 14, 109-12.

Dick, I.D. 1965. "Extreme Value Theory and Earthquakes". Proc. Third World Conf. Earthq. Eng. Wellington, N.Z. III, 45-53.

Dickenson, G.E. and Adams, R.D. 1967. "A Statistical Survey of Earthquakes in the Main Seismic Region of New Zealand. Part 3 - Geographical Distribution!" N.Z. J. Geol. Geophys. 10, 1040-50.

Eiby, G.A. 1971. "Frequency of Earthquake Occurrence in New Zealand." J. Roy. Soc. N.Z. 1, 78-82.

Hayes, R.C. 1936a. "Intensity Distribution in New Zealand Earthquakes." N.Z. J. Sci. Tech. XVIII, 508-11.

Hayes, R.C. 1936b. "The Seismicity of New Zealand Cities and Towns." N.z. J. Sci. Tech. XVIII, 608-12.

Hayes, R.C. 1941. "The Seismicity of New Zealand. N.z. J. Sci. Tech. XXIII, 49B-52B.

Hayes, R.C. 1943. "On Earthquake Distribution in New Zealand! J. Sci. Tech. XXIV, 236B-8B.

N.Z.

Lensen, G.J. 1968. "Analysis of Progressive Fault Displacement During Downcutting at the Branch River, South Island, New Zealand". Geol. Soc. Am. Bull. 79, 545-56.

Lensen, G.J. 1976. "Late Quaternary Tectonic Map of New Zealand $1: 50,000 "$. Sheets N28D, 028C, N29B Hillersden (lst ed) and 028D, P28C Renwick (lst ed), DSIR, Wellington.

Lensen, G.J. 1977. "Late Quaternary Tectonic Map of New Zealand $1: 2,000,000 "$ (1st ed) NZ Geol. Surv. Misc. Series Map 12, DSIR, Wellington.

Matuschka, T. 1980. "Assessment of Seismic Hazard in New Zealand". School of Engineering, University of Auckland, Report No. 223, 214pp.

Medvedev, S.V. (Editor) 1976. "Seismic Zoning of the USSR! USSR Academy of Sciences. Israel Program for Scientific Translations, Jerusalem, $533 \mathrm{pp}$.

Peek, R. 1980. "Estimation of Seismic Risk for New Zealand, a Seismicity Model and Preliminary Design Spectra". Dept of Civ. Eng., Univ. of Canterbury, Report 80/21,84pp.

Peek, R.; Berrill, J.B. and Davis, R.O. 1981. "A Seismicity Model for New Zealand." Bull. N.Z. Nat. Soc. Earthq. Eng. 13, 355-64.
Smith, W.D. 1976a. "A Computer File of New Zealand Earthquakes." Bull. N.z. Nat. Soc. Earthq. Eng. 9, 136-7.

Smith, W.D. 1976b. "Statistical Estimates of the Likelihood of Earthquake Shaking Throughout New Zealand. Bull. N.z. Nat. Soc. Earthg. Eng. 9, 213-21.

Smith, W.D. 1978a. "Spatial Distribution of Felt Intensities for New Zealand Earthquakes! N.Z. J. Geol. Geophys. 21, 293-311.

Smith, W.D. 1978b. "Earthquake Risk in New Zealand: Statistical Estimates." N.z. J. Geol. Geophys. 21, 313-27.

Standards Association of New Zealand 1976. "Code of Practice for General Structural Design and Design Loadings for Buildings. NZS 4203." $80 \mathrm{pp}$.

Vere-Jones, D. 1973. "The Statistical Estimation of Earthquake Risk" Bull. N.Z. Nat. Soc. Earthq. Eng. $6,122-27$

Vere-Jones 1975. "Stochastic Models for Earthquake Sequences". Geophys. J.R. astr. Soc. $42,811-26$.

Walley, P. 1976. "The Estimation of Earthquake Risk in New Zealand! Applied Maths Division, DSIR, Wellington. Tech. Rept. No. 49 , 8 lpp.
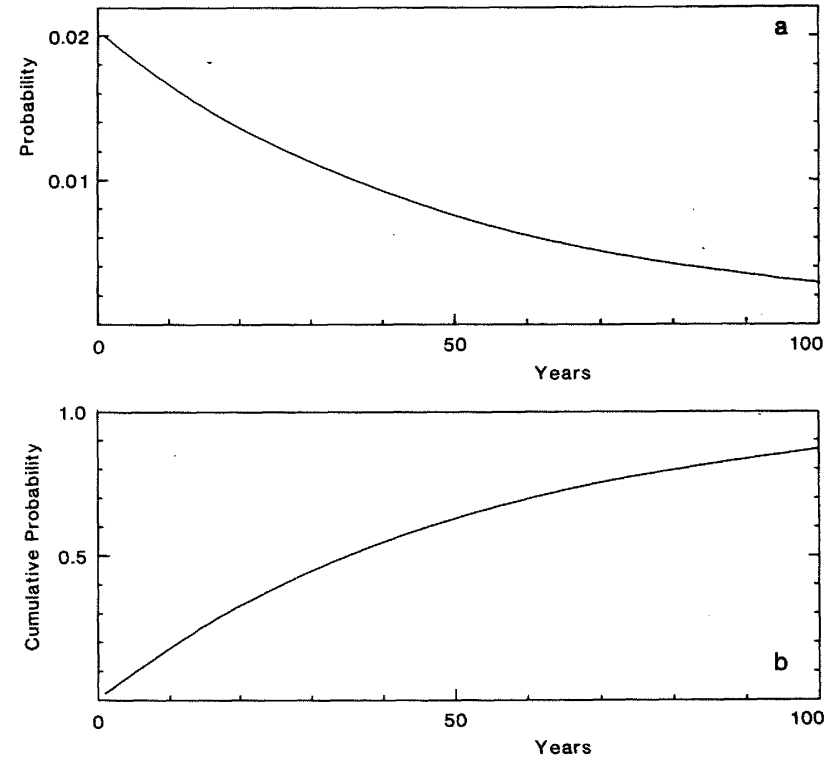

Fig. 1 (a) The Poisson probability that the next occurrence of an event will be in a particular year, given an annual probability of 0.02 .

(b) The Poisson probability that an event with an annual probability of 0.02 will occur within a given time interval. 